\title{
Refrações medievais em Agustina Bessa-Luís: Leonor Teles e Lady Macbeth
}

\author{
Ana Maria Machado \\ Universidade de Coimbra \\ http://orcid.org/0000-0003-4392-2999
}

[Recibido, 10 fevereiro 2021; aceptado, 6 maio 2021]

\begin{abstract}
[Machado, A.-M. (2021). Refrações medievais em Agustina Bessa-Luís: Leonor Teles e Lady
Macbeth. Boletín Galego de Literatura, 58, "Estudos", 29-44]

DOI http://dx.doi.org/10.15304/bgl.58.7493
\end{abstract}

RESUMO O estudo da receção da Idade Média nos séculos ulteriores, sobretudo na sua vertente criativa (Ferré, 2010) revela simultaneamente imagens do medieval e interrogações sobre o tempo presente. Partindo dos hipotextos medievais, Agustina Bessa-Luís reconfigura a imagem de Leonor Teles através da lente de Lady Macbeth. Na abordagem do conto "Leonor Teles", inserido em Fama e Segredo na História de Portugal (2006), estudam-se as perceções do passado e interroga-se o sentido, as razões e as modalidades dessa presença medieval no imaginário contemporâneo, sendo certo que, como lembra Gómez Redondo (2006, p. 324), "toda pesquisa del pasado se practica para iluminar con ella el presente; no se ponen en pie estos 'mundos posibles' por simple ejercicio de arqueología literaria". Numa perspetiva comparativa e sob o prisma do medievalismo, conclui-se que a autora concilia a atemporalidade com a referencialidade medieval para representar Leonor Teles num "sublime negativo" (Bloom, 1997) em que supera Lady Macbeth.

PalAVRas CHAVE: Medievalismo; imagologia; crónicas medievais; Mário Cláudio; Agustina Bessa-Luís.

ABSTRACT The study of the reception of the Middle Ages throughout the later centuries, especially in its creative aspect (Ferré, 2010), reveals both images of the medieval and questions about the present time. Starting from medieval hypotexts, Agustina Bessa-Luís reshapes Leonor Teles profile through the lens of Lady Macbeth. In the approach of the short story "Leonor Teles", included in Fama e Segredo na História de Portugal (2006), we study the perceptions of the past and question the meaning, reasons and modalities of this medieval presence in the contemporary imagination -being certain that, as Gómez Redondo recalls (2006, p. 324), "all past research is practiced to illuminate the present; these 'possible worlds' do not rise by simple exercise of literary archaeology". In a comparative perspective and under the prism of medievalism, we conclude that the author reconciles timelessness with medieval referentiality to portrait Leonor Teles in a "negative sublime" (Bloom, 1997) where she surpasses Lady Macbeth.

KEYwords: Medievalism; imagology; Medieval Chronicles; Mário Cláudio; Agustina Bessa-Luís. 
Se os amtiigos que louvarom as nobres molheres, viverom no tempo da Rainha dona Lionor, muito errarõ em seu escprever, se a nom poserom no comto das mui famosas. Porque sse o dom da fremosura de todos mui preçado, fez a alguũas gaanhar perpetuall nome, deste ouve ella tam gram parte, acompanhado de prazível graça, que aquella que o mais desejar podesse, seeria assaz de comtemta, do que a natureza a ella proveeo; desi com esto sageza de costumes e gramde avisamento; e de nehuũa cousa que a prudemte molher perteemça, era ignoramte. (Lopes, 1977, p. 31)

1. É nestes termos que, no capítulo XV, da Parte Primeira da Crónica de D. foão I, Fernão Lopes traça o retrato de Leonor Teles, tornando visível a sedução que a personagem exerce sobre o autor. As páginas que o cronista lhe dedicou, tanto aqui como anteriormente, na Crónica de D. Fernando, fixaram para a posterioridade uma imagem em que a beleza se alia ao calculismo e à aleivosia, num panegírico conjugado com a representação negativa que o cronista dela faz e com o que, sobre a rainha continuará a relatar: desde o seu casamento com o D. Fernando - desigual, por não ser ela filha de rei -, à consequente censura dos conselheiros régios e do povo ou aos castigos que, sendo rainha, inflige a quem censurara o seu matrimónio, bem como à recompensa dos que a serviam, passando pela maquinação da morte de sua irmã Maria Teles - por receio de que a fama de seu marido, o Infante D. João, filho de Pedro e Inês, a viesse a afastar do poder -, e também pelo conluio que conduziu à prisão D. João, Mestre de Avis, também ele filho do rei D. Pedro; sem esquecer ainda o adultério de Leonor Teles com o Conde Andeiro e a conspiração com o rei de Castela, contrariando os termos da sucessão régia firmados no tratado de Salvaterra de Magos, num comportamento sempre pautado pela hipocrisia e pela dissimulação.

Embora não se possa negligenciar que a ênfase neste retrato disfórico da rainha e na sua infidelidade matrimonial integra a estratégia do cronista que deste modo lança suspeitas sobre a legitimidade da sucessão ao trono de D. Beatriz, a filha que Leonor Teles tivera com o rei D. Fernando, importa relevar que, contrariamente a outras personagens em queda, nunca a figura da rainha foi recuperada pelo narrador, atenuando, eventualmente, o seu maquiavelismo.

O caráter romanesco da personagem e a linguagem saborosa com que o cronista lhe desenha os contornos colocam-na a par de outras figuras femini- 
nas que a posteridade imortalizou, como Inês de Castro, a que obteve maior fortuna, D. Teresa, mulher do conde D. Henrique, ou Filipa de Lencastre, casada com D. João I, todas elas referências incontornáveis do imaginário medieval feminino e inspiradoras frequentes da literatura posterior.

2. Na senda de trabalhos anteriores sobre o medievalismo literário português e prosseguindo a investigação da receção criativa da Idade Média nos séculos que lhe sucedem (Gentry e Müller, 1991; Emery, 2009; Ferré, 2010), elejo agora como objeto de estudo a recomposição da imagem de Leonor Teles. Este foco na literatura é justamente um dos eixos de um projeto mais amplo que, de acordo com a série "Medievalism", da editora Boydell \& Brewer, abarca "post-medieval constructions and manifestations of the Middle Ages [...] in all fields of culture, from politics and international relations, literature, history, architecture, and ceremonial ritual to film and the visual arts" (https://www.cambridge.org/core/series/medievalism/A285DFD5EF175DB8A83062D37CCAC691\#) e que, nos termos de David Matthews (2015), inclui o modo como, nos períodos subsequentes à Idade Média, se reutilizaram motivos, temas, géneros e tópicos que lhe são próprios. A estes itens, acrescenta-se agora a categoria personagem e a sua recriação numa narrativa novecentista.

Partindo dos hipotextos medievais, analisarei o modo como Agustina Bessa-Luís (1922-2019) reescreveu as intrigas medievais em que a rainha D. Leonor se enredou e as perceções do passado que a autora revela, ao mesmo tempo que interrogo o sentido, as razões e as modalidades da presença medieval no seu imaginário. De facto, tal como afirma Elizabeth Emery (2009, p. 78), em "Medievalism and the Middle Ages", "The common denominator among the multiple, interdisciplinary forms medievalism takes is method: how and why various individuals and institutions have chosen to engage with the Middle Ages." Como resposta a esta questão, Gómez Redondo (2006, p. 324) sugere que "toda pesquisa del pasado se practica para iluminar con ella el presente; no se ponen en pie estos 'mundos posibles' por simple ejercicio de arqueología literária”.

De facto, embora a compreensão literária do passado esteja, em todas as épocas, sujeita ao filtro imaginativo, com naturais consequências na relativização da referencialidade primária, como bem lembrou o pós-estruturalis- 
mo, a pregnância do tempo presente é incontornável. Os mundos possíveis podem apresentar-se como uma forma de sobrevivência ou de persistência, conjugando o intertexto medieval com a interpretação que os novos autores fazem do passado, como uma forma de iluminarem o presente para o qual procuram respostas nessa época recuada (Gómez Redondo, 2006) ou como uma recriação da Idade Média própria de cada época e dos condicionamentos que a fundamentam.

As obras literárias que procedem à imitação criativa do mundo medieval são objeto de uma reflexão sobre a dialética entre a permanência e a mudança, ou, dito de outro modo, sobre aquilo que Michèle Gally (2000, p. 9) designa por "remanência", a propósito da herança medieval que interroga o passado para interrogar a sua época, tal como o homem medieval interrogou o seu tempo. Este movimento pressupõe uma alteridade endógena à literatura e ao mundo medievais, como já na década de 80 notavam autores como Zumthor ou Jauss, e é esta mesma alteridade que impede a transposição de utensílios críticos e teóricos estranhos a esse passado longínquo. Justamente a estética da receção e a literatura comparada, com o estudo da alteridade e das permanências, favorecem a observação da sequência e do cruzamento de concretizações e de intertextos que ligam as reescritas medievalistas ao seu passado medieval, bem como a análise do modo como ele é reconstruído. E é devido a este processo, que Ferré e Gally (2014, p. 44) chamam a atenção para um aspeto nuclear do medievalismo: "Ce serait alors la littérature médiévale en elle-même qui deviendrait un outil théorique pour penser l'invention poétique et fictionnelle la plus contemporaine”.

Por esta razão, e também numa perspetiva comparada, o olhar do medievista é essencial e favorece a perceção de uma memória que se constrói, por vezes, à margem da alteridade medieval (Zumthor, 1972; Jauss, 1977; Nichols, 2005). No caso presente e na interrogação que o medievalismo propõe, as fontes medievais compulsadas, em particular as crónicas de Fernão Lopes (c.1380-c.1460), oferecem-se como o tal "instrumento teórico" (Ferré e Gally, 2014, p. 44), sendo determinantes para o estudo das revisitações imaginativas que Agustina Bessa-Luís oferece no conto "Leonor Teles", incluído em Fama e Segredo na História de Portugal (2006).

Embora a imaginação da autora a impeça de se circunscrever às fontes, a sua presença, visível na relativa fidelidade com que as segue, cita e parafraseia 
revela o que M. J. Toswell (2009, p. 72) designa pelo impulso escolar que caracteriza o medievalismo e a sua busca do autêntico, "not just in the sense of studying those who produce medievalism, but in the sense that those who nowadays produce medievalist texts endeavor mightily to construct themselves as true scholars". Por consequência, e seguindo o que este autor propõe como sendo o vasto espectro do medievalismo que dista entre a fantasia e o realismo, o resultado da revisitação de Agustina aproxima-se necessariamente deste último.

3. Não é a primeira vez que a autora, afeita ao romance histórico, aborda temas medievais. A Crónica do Cruzado Osb, em 1976, a biografia de Santo António, em 1979, ou as Adivinhas de Pedro e Inês, em 1983, contam-se entre recriações históricas de outros tempos e precedem o conjunto de protagonistas que reúne em Fama e segredo na bistória de Portugal, numa súmula do que a autora considera as dúvidas mais instigantes da história portuguesa. Na esteira de autores como Aquilino Ribeiro (1885-1963) e os seus Príncipes de Portugal. Suas grandezas e misérias, de 1952, ou, mais recentemente, em 2004, do Triunfo do amor português ${ }^{1}$, de Mário Cláudio (n. 1941), Agustina Bessa-Luís retoma a ficcionalização de personalidades notáveis numa síntese seletiva e remanente - entre permanente e mutável (Gally, 2000) -, subordinada ao desvendar das suas sombras, uma das obsessões confessadas nos seus romances históricos (Machado, 2017).

Tal como o Triunfo do amor português, também Fama e segredo na história de Portugal é uma obra cartonada, graficamente cuidada e, ilustrada, numa primeira edição, por Luís Miguel Castro, e, numa segunda, por Lucy Pepper $(2010)^{2}$. A materialidade do livro reflete uma inequívoca sinalização do poder simbólico e da revisão patrimonial que, conscientemente, a autora oferece à pátria. A sua divisão em doze capítulos, que Agustina designa por "Óperas”, assinala a multimodalidade, a ostensão, e o excesso dos dramas, matérias possíveis do que Richard Wagner denominou a obra de arte total. No caso concreto da "ópera III", dedicada a "Leonor Telles", acresce a consciência do potencial trágico e operático com que a autora olha para estas páginas da literatura medieval: "Fernão Lopes encontra em Leonor Telles uma figura

Neste caso, a seleção ultrapassa os governantes, estendendo-se também a escritores.

2 A obra teve duas edições com formato, capa, ilustração e grafismo diferentes. 
que ultrapassa a Macbeth, faltando-lhe a mão que foi de Shakespeare." (Bessa-Luís, 2010, p. 43)

4. Esta analogia revela-se nuclear no conto de Agustina, pelo que, na análise do seu medievalismo, procurarei demonstrar como a comparação entre Leonor Teles e Lady Macbeth da tragédia shakespereana (1606) institui um protocolo narrativo que impele a autora a criar uma nova personagem, recuperando teses que expusera noutras obras ou modelando a historiografia oficial sempre que ela se não adequa à imagem que pretende traçar da rainha.

Para tal, começarei por observar o diálogo que a autora estabelece com Fernão Lopes, comentando a sua arte narrativa - subterfúgio metatextual para apresentar o programa poético da romancista -; dialogando com ele, como quando complementa o seu comentário assombrado a propósito da intenção de casamento de D. Fernando com sua irmã D. Beatriz - "determinou em sua vontade de casar com ella, cousa que atá aquel tempo semelhante nom fora vista" (Lopes, 1975, p. 198) - com a analogia com o "caso bíblico de Tamar e Amnon" (Bessa-Luís, 2010, p. 44); ou contrapondo-lhe uma relação diversa com a personagem, exemplificada na sedução que Leonor Teles exerce na autora, não já pela sua beleza e inteligência, como no caso de Fernão Lopes, mas pela sua majestade. Num segundo momento, analiso o modo como o confronto entre a protagonista e as suas vítimas determina a estrutura do conto ao mesmo tempo que se erige em pedra angular da construção desta hiper Lady Macbeth.

5. No conto "Leonor Teles", a etiqueta musical é suscitada pela própria teatralidade que a autora reconhece no tom usado pelo cronista "como se visse no espaço títeres e não gente viva e de corte", ao que acrescenta "Mas não se esquece Fernão Lopes de dar à narrativa um tom teatral” (Bessa-Luís, 2010, p. 43). Fica assim dado o mote para a perspetiva a adotar nesta encenação operática da Idade Média. Contudo, neste conto, não se trata tanto de insistir numa atmosfera medieval, aqui natural apenas por inerência, mas de centrar o relato na reconstrução de uma personagem que, aos olhos da autora e num processo usado em alguns dos seus romances, tem como analogon, inferior,

3 Cito pela 2. ${ }^{a}$ edição da obra. 
Lady Macbeth. Fica assim registada a referência condutora da obra e da conformação da personagem. Por consequência, como se verá, o desenho da personagem é construído por fragmentos, muito ao jeito de Agustina, e por uma seleção dos quadros em que a protagonista contracena com as suas sucessivas vítimas - D. Fernando, seu marido (a quem é concedida apenas uma atenção residual), Fernão Vasques, o Infante D. João e Maria Teles, o conde Andeiro e o Mestre de Avis - ou em que Leonor Teles é, ela própria, a vítima, emergindo aqui em pleno esplendor da sua dignidade de rainha, um traço que em Fernão Lopes surge mais desfocado.

Antes, porém, de a colocar em cena, e também à maneira de Fernão Lopes, a escritora apresenta metatextualmente o seu programa ficcional, mediante uma apreciação da arte do cronista, ponto de partida para o diálogo que com ele mantém ao longo da obra, sublinhando sintonias e divergências, mas também reconhecendo tácitas afinidades poéticas.

De facto, apesar da limitação que Agustina reconhece no cronista, a atitude da autora não é concorrencial, mas antes reflexiva, questionadora e igualmente romanesca, como se depreende quando, comentando o labor de Fernão Lopes, assevera: "Ele é um novelista e não deixa escapar a matéria da sua história, que é outra coisa do que subscreve o Tombo.” (Bessa-Luís, 2010, p. 45). Além da aproximação de estatutos - ambos são novelistas -, a dimensão subjetiva da crónica - também comum à ficção -, marcada no itálico, bem como os particularismos dos relatos de Fernão Lopes provêm do que Agustina considera ser uma conciliação entre a tarefa de cronista e o estatuto social do autor:

Que lhe encontrem erros cronológicos, ignorâncias palmares, preferências, caprichos de interpretação, isso quer dizer que, no meio da sua obrigação de cronista, encontra maneira de manifestar o seu humor de pequeno cortesão, de quem sabe demasiado para escutar às portas, o que o deixa mais ilustrado do que se lesse as cartas, as sentenças que fazem prova. Ele não quer fazer prova; para isso tinha a vida ameaçada. E quem era ele para nomear pessoas e revelar-lhes o que sabiam, o que ouviam entre a cozinha e o claustro, entre o pomar e o pátio? Quem é ele? Um criado, menos do que um confessor, mas, como este, bem informado. As suas fontes são mais do que secretas; são populares e não eruditas. (Bessa-Luís, 2010, p. 44-45)

Uma tal apresentação do labor do romancista - assim o designa Agustina no início do conto -, que já antes afastara do estereótipo do amanuense 
- "Não é um mero anotador de factos ou um conversador com o passado; ou, melhor ainda, um vassalo da pena e do tinteiro, sempre com o dedo tingido de tinta e algum borrão no punho da camisa” (Bessa-Luís, 2010, p. 43) -, parece equivaler de novo a uma aproximação implícita dos perfis entre os dois escritores, não estivesse o secretismo consagrado no título da obra; um segredo descoberto por mediação de Fernão Lopes e prolongado por artes de adivinhação na reescrita contemporânea, como foi explicitamente assumido em Adivinhas de Pedro e Inês, obra cujas conclusões aqui reitera. Além disso, este prolegómeno não pode deixar de lembrar o que precede a Primeira Parte da Crónica de D. Foão I, pese embora a subversão, quase paródica, da proclamação de verdade que ali se desenvolvia ${ }^{4}$. Quiçá a benevolência que Agustina manifesta em relação às "ignorâncias palmares" ou aos "caprichos de interpretação" de Fernão Lopes não é, também ela, uma captatio beneuolentiae em relação aos erros que, como se verá, ela própria comete - inadvertida ou caprichosamente.

Talvez seja justamente devido a esta sintonia de perfis que Agustina reescreve muito de perto o percurso de Leonor Teles, desde a sua entrada na vida de D. Fernando, relatado na crónica homónima de Fernão Lopes, até ao seu refúgio em Castela após o assassinato do amante às mãos do Mestre, narrado na Primeira parte da Crónica de D. Foão I. O que há, então, de novo neste conto? Por um lado, a capacidade de síntese e a emulação de alguns traços de linguagem, como sendo a classificação do cronista como um "tangedor de elementos” (Bessa-Luís, 2010, p. 43) ou a escrita arcaica do apelido Telles. Por outro, o olhar distanciado sobre o passado que a autora recupera, citando ou parafraseando as crónicas que o fixaram, e que analisa, quer questionando as fontes do guarda-mor da Torre do Tombo, quer ilustrando os comportamentos relatados com situações históricas análogas de outros tempos (o amor vingativo como Einstein, a conquista amorosa como a de Napoleão III, a morte do Andeiro como a de César), aventando, em discurso modalizante, outras hipóteses em torno de Leonor Teles. Ao longo deste processo, Agustina rebate ainda a fama da misoginia de Fernão Lopes e, relativamente à rainha, desenvolve o seu caráter vingativo e também a sua majestade.

\footnotetext{
4 Vejam-se os termos em que, no prólogo da crónica, Fernão Lopes reitera o seu propósito de dizer a verdade: "nosso desejo foi em esta obra escprever verdade, sem outra mestura, leixando nos boõs aqueçimentos todo fimgido louvor, e nuamente mostrar ao poboo, quaaes quer comtrairas cousas, da guisa que aveherõ." (Lopes, 1977, p. 2).
} 
Sobre a misoginia do cronista, a autora nega que ele tenha feito "da pluma uma adaga" (Bessa-Luís, 2010, p. 43), justificando a disforia do retrato fernãolopino pela abundância de aleivosias praticadas pela personagem, defendendo não haver, da parte do cronista, qualquer parti pris em relação às mulheres. No diálogo que empreende com o cronista, Agustina desenvolve igualmente a faceta oposta, ou seja, o que Óscar Lopes dizia ser a admiração, "no plano trágico" (Bessa-Luís, 2010, p. 46), que Leonor Teles exercia em Fernão Lopes. Deste modo, a par das mortes semeadas pela protagonista, a ilustrar a sua dimensão sombria, Agustina sublinha, mais diretamente do que Fernão Lopes, a majestade do seu comportamento, quando, depois de o Mestre ter assassinato o conde Andeiro, amante de Leonor Teles, lhe manda "perguntar (...) se também havia de morrer" (Bessa-Luís, 2010, p. 51). E, sobremaneira, na "entrevista de D. João, o Mestre de Avis, e os seus apaniguados, com a rainha. Nunca outra mulher foi mais rainha do que ela. Porque, entre a dor e o temor, mantém alta a fronte e escarninho o sorriso" (Bessa-Luís, 2010, p. 52), uma expressão clara do sublime negativo que Harold Bloom (1997) identifica em Lady Macbeth. Num retrato tão breve como o que Agustina traça, a grandeza da rainha alcança um maior impacto do que na crónica medieval, mesmo apesar de a autora considerar a narração deste encontro "uma página das mais belas que escreveu Fernão Lopes” (Bessa-Luís, 2010, p. 52).

Já no que toca ao reconhecimento explícito da falta de mão de Fernão Lopes para pintar o maquiavelismo da rainha, a estrutura que a autora adota no conto parece pretender suprir essa lacuna. Para tal, não só transforma a deuteragonista e oponente das crónicas em protagonista destinadora do mal, como circunscreve cirurgicamente os quadros protagonizados pelas principais vítimas de Leonor Teles, permitindo eleger a constelação de personagens mais adequada à sua caraterização.

6. O recorte traçado implica, naturalmente, a eliminação dos capítulos que, nas crónicas, medeiam as cenas selecionadas por Agustina, o que concorre para explorar novas relações de causalidade entre as partes e para potenciar o pathos por via de uma sucessão que suprime as placas giratórias que mostram cenas simultâneas, bem como os perspetivismos narrativos próprios do cronista.

Na trama assim re-urdida, ganham relevo cinco vítimas cronologicamente ordenadas e com distintos graus de responsabilidade e de fatalidade: o rei 
D. Fernando, que Leonor Teles seduz; Fernão Vasques, o alfaiate que encabeçou a contestação do casamento régio; o infante D. João e a sua mulher Maria Teles; o conde Andeiro e, finalmente, D. João, Mestre de Avis e futuro rei de Portugal. O primeiro representa a debilitação do poder; o segundo, a contestação popular gorada; o terceiro, o poder tentacular e cruel da rainha e a ameaça de sucessão abortada; o quarto, a destituição do poder de Leonor Teles; e, o último, a conquista da alternativa à sucessão régia.

No conjunto de fragmentos evocativos da história pregressa, o destino do infante D. João e de sua mulher, D. Maria, é talvez o caso mais romanceado, tanto por Fernão Lopes quanto por Agustina. Escolho-o por isso para ilustrar as remanências visíveis na permanente teia maléfica em que se move a protagonista e na tragicidade operática da intervenção especulativa e sentenciosa da autora, cujo alcance só é percetível considerando o intertexto de Fernão Lopes. Este é, de facto, o episódio em que a leitura que Agustina faz de Leonor Teles mais se singulariza e para o qual necessitou de reescrever, ou de confundir, o comportamento do infante.

A analogia que a autora inicialmente estabeleceu com Lady Macbeth constitui uma lente interpretativa que confere espessura à protagonista, cruzando memórias literárias de figuras distintas. E se, no entender de Agustina, já em Fernão Lopes Leonor Teles superava em maldade a personagem ${ }^{5}$ da tragédia shakespeareana, a reinterpretação da protagonista que assim se anuncia dita a sua reconfiguração, nomeadamente através da multiplicação dos crimes cometidos ${ }^{6}$ com inalterável frieza de caráter.

Em fundo, persistem algumas semelhanças com a tragédia isabelina, nomeadamente na relação inicial entre o casal Macbeth - nobres escoceses em

5 Um sintoma da sua perfídia e sangue-frio pode ler-se logo no Ato I, cena VII, quando, perante as hesitações do marido em matar o rei da Escócia, Lady Macbeth contrasta-o com um exemplo dos extremos da sua intrepidez malévola: "Eu já amamentei e sei com que ternura se ama a criança a quem damos leite; mas enquanto ela se sorrisse para mim, teria retirado o bico do seio das suas gengivas dedicadas, e ter-the-ia rebentado os miolos se tivesse jurado fazê-lo como vós jurastes fazer isto." (Shakespeare, 1987, p. 67).

6 Em "Leonor Telles", a rainha manda matar Fernão Vasques (Bessa-Luís, 2010, p. 46), enquanto na Crónica de D. Fernando o castigo régio reside na ordem de prisão do alfaiate (Lopes, 1975, p. 214). E, no último ato de $A$ tragédia de Lady Macbeth, no seu delírio sonâmbulo, a agora rainha estranha: "Quem pensaria que o velho [rei] tinha tanto sangue no corpo" e, na fala seguinte, pungentemente, interroga-se: "Por que nunca estarão estas mãos limpas?" (Shakespeare, 1987, p. 193). 
ascensão -, percebe-se um contraste entre uma certa pusilanimidade do marido e o domínio da mulher, semelhante ao que une D. Fernando e Leonor Teles. É em reação a essa fragilidade que Lady Macbeth instiga o marido, hesitante, a matar o rei e a usurpar-lhe a coroa ${ }^{7}$. Posteriormente, o afastamento de Macbeth, tornado sanguinário, reduz a grandeza que o casal se tinha prometido e Lady Macbeth, inicialmente mais determinada, cai numa loucura que, segundo Harold Bloom, excede o trauma causado apenas pela culpa.

Ora, se o destino de Lady Macbeth se revela mais trágico, quer pelo abandono do marido, entregue à máquina de morte, quer pelo delírio psíquico que a conduz ao suicídio, para o retrato excessivo que Agustina quer negro não são suficientes as maquinações assassinas relatadas por Fernão Lopes, pelo que, mantendo o registo realista, por fidelidade à historiografia oficial, multiplica o perfil calculista, vingativo e assassino de Leonor Teles, nos vários quadros evocados.

No relato da morte de Maria Teles, na sequência do seu casamento com o infante D. João, não bastava a Agustina a confirmação do receio que a rainha tinha do "espaço demasiado avantajado" que o infante "ocupava no reino" (Bessa-Luís, 2010, p. 46). Era necessário justificar esta simpatia para dar coerência ao crime que afastaria o infante D. João da cena política. Para tal, a autora vai retomar uma das teses defendidas em Adivinhas de Pedro e Inês (Machado, 2017), mantendo o registo modalizante que ali utilizara: "Decerto continuava de pé o facto, nunca esclarecido, do casamento de D. Pedro com D. Inês." (Bessa-Luís, 2010, p. 46). Na opinião da autora, este matrimónio ocorrera antes do casamento do infante D. Pedro com D. Constança, o que explicaria que o rei não se lembrasse da data de seu matrimónio, conforme se lê na Crónica de D. Pedro de Fernão Lopes. Contudo, em Agustina, a razão deste esquecimento diverge da que o cronista apresentara. No entender da autora, trata-se de um falso lapso de memória para encobrir a consciência do risco de bigamia que comprometeria a legitimidade sucessória de D. Fernando, filho de D. Pedro e de D. Constança. Postulando que o povo comungava desta "intriga amorosa",

7 Veja-se o discurso que Lady Macbeth dirige ao marido, no final do Ato I, cena VII: "[...] enroscai a vossa coragem no devido lugar e não falharemos. Quando Duncan [rei da Escócia] estiver a dormir [...] conquistarei os seus dois camareiros com vinho e cerveja até que a memória, guardiã do cérebro, seja apenas fumo e os crânios sejam alambiques. Quando, encharcados de vinho, jazerem como mortos, que poderemos, vós e eu, fazer ao indefeso Ducan? Porque não atribuir a culpa do nosso grande crime aos seus bêbedos guardas?" (Shakespeare, 1987, p. 68). 
Agustina encontra na partilha deste segredo a razão da "estranha predileção" do povo pelo infante D. João, filho de Pedro e Inês, preenchendo de novo lacunas da crónica no que toca à razão da simpatia que o infante inspirava ${ }^{8}$.

Ao mesmo tempo, prolongando a hipótese de bigamia silenciada, a autora contraria a narrativa oficial de Fernão Lopes a quem competia legitimar a dinastia de Avis, motivo pelo qual insinuara que, ao contrário do que rezava a declaração oficial de casamento de D. Pedro, este não teria casado com Inês de Castro. Deste modo, o registo cronístico colocava em igualdade de circunstâncias D. João mestre de Avis e o Infante D. João, pois os dois eram filhos do rei e putativos herdeiros da coroa. Divergências deste jaez demonstram que, diferentemente do cronista, Agustina não é movida por uma agenda política, mas pelo esforço de apreensão das sinuosidades da mente humana, pretendendo explicar motivações, segredos, sentimentos, personalidades e, assim, tornar compreensíveis os esboços de figuras remotas que apenas a historiografia, apesar de romanceada, preservou.

Na versão de Agustina, a legitimidade do casamento entre Pedro e Inês é, portanto, uma peça-chave a justificar a perseguição mortal que Leonor Teles move ao infante D. João. Não é todavia suficiente. E, com a desenvoltura com que muito soltamente reescreve a história, Agustina atribui ao infante D. João a recusa em beijar a mão à rainha, quando, na realidade, e segundo relata Fernão Lopes, fora D. Dinis, seu irmão, que cometera essa afronta ${ }^{9}$. Esta troca, deliberada, ou não - recorde-se como, no início, a autora desvalorizara os erros de Fernão Lopes em prol dos segredos que desvelava (Bessa-Luís, 2010, p. 44-45), como se também advogasse em causa própria -, converte a intriga com que Leonor Teles vitima sua irmã, entretanto casada com o infante D. João, numa consequência do seu perfil vingativo e da sua ambição desmedida de poder, uma outra pedra de toque da sua personalidade. Além de o infante D. João ser favorito do reino, Leonor Teles "Já via a irmã a impor-se ao povo e aos nobres afeiçoados ao caso triste de D. Inês de Castro e, por isso inclinados a ver D. João no trono que lhe pertencia por direito" (Bessa-Luís, 2010, p. 48). Por este motivo, Leonor Teles recompõe a trama que Fernão Lopes descreve nos capítulos CI a CIII da Crónica de D. Fernando: desagradada com

8 A razão apresentada na Crónica de D. Fernando prende-se com o facto de o infante ser "o mayor no rreino" (Lopes, 1975, p. 216).

9 Ver "o ifante dom Denis [...] nunca lh'a [maão] quis beijar" (Lopes, 1975, p. 216). 
o casamento da sua irmã, Maria Teles, com o infante D. João, a rainha faz-lhe saber que gostaria de o ver casado com sua filha D. Beatriz. Cumpria, pois, dissolver o casamento por morte, o que só se poderia fazer legitimamente por crime de adultério. Neste ponto o cronista cala, mais uma vez, a responsabilidade da falsa acusação de infidelidade que instigou o assassínio de Maria Teles, deixando em aberto a dúvida sobre o autor da difamação. E, também de novo, Agustina tira partido desta incerteza para lançar a hipótese cruel: "Talvez ela [Leonor Teles] própria a mandasse matar e arrastasse D. João para a cena de sangue que o culpava a ele" (Bessa-Luís, 2010, p. 48). A materialização do assassinato da irmã, sem a rede de mediações descrita por Fernão Lopes ${ }^{10}$, amplifica a culpa da rainha, agora potencial responsável direta tanto pela morte de Maria Teles, como pela incriminação do cunhado, meio-irmão de seu marido. Por outro lado, com a hipótese de inocência do infante, a estatura de Leonor Teles cresce ainda mais em dissimulação e crueldade: "com uma alma maviosa quando se tratava de agradar; mas sombria e determinada quando o poder a cegava." (Bessa-Luís, 2010, p. 48-49).

A coroar esta evocação, e à maneira de Fernão Lopes que recorre a "ditos de filosofia como os letrados têm por obrigação” (Bessa-Luís, 2010, p. 55), também Agustina encima a alusão a esta tragédia com um aforismo: "as mulheres não perdoam que lhes desprezem as glórias” (Bessa-Luís, 2010, p. 46). O tom sentencioso e generalizador não só enquadra o comportamento da rainha num estereótipo feminino, como acrescenta à razão política motivos individuais como sejam a ofensa pessoal cometida pelo infante quando, na versão de Agustina, se não vergou perante a rainha. Por conseguinte, na linha da exacerbação da ambição e calculismo de Leonor Teles, o desfecho fatal é a resposta a uma vingança em que a rainha aguardou friamente o tempo azado e à estratégia necessária para garantir a permanência da coroa. Não se trata de a usurpar, como em Lady Macbeth, mas de a preservar por meios igualmente assassinos. Daí a insistência, de novo aforística, que interpreta o excesso de poder da rainha como exemplo de uma verdade universal, sem tempo nem lugar: "O poder é pior do que a tortura mais cruel, porque se aplica ao desejo na sua fatalidade.” (Bessa-Luís, 2010, p. 49).

10 No capítulo Cl da Crónica de D. Fernando, descreve-se a trama de Leonor Teles que pede ao seu irmão que fizesse saber ao infante $D$. João como ela gostaria de o ver casado com sua filha $D$. Beatriz, o que lhe asseguraria a sucessão no trono. Para tal, uma voz não identificada difamou $D$. Maria, acusando-a de trair o marido, ficando assim legitimada a morte brutal que ocorreu às mãos do infante. 
Tanto nesta trama de amor e morte, como nos demais quadros com que a autora reconfigura a protagonista, assiste-se sobretudo a evocações revisitadas do passado, mais do que a relatos das cenas convocadas. Supõe-se, pois, que o leitor partilha da mesma enciclopédia da autora e que é com base nesta cumplicidade que este se permite acompanhar a versão de Agustina, escrita a partir das "coisas que o coração lembra sem as ter vivido" (Bessa-Luís, 2010, p. 56), tal como acontecera com o seu predecessor medieval e como nota neste final do conto, a um outro propósito, ainda que a observação seja extensível a toda esta ópera.

Concluindo, a imitação criativa do mundo medieval está, no conto "Leonor Telles", confinada à reconstrução da personagem, tendo como analogon a figura de Lady Macbeth e, como fonte inspiradora da ficção, as crónicas régias. Esta "imaginação da Idade Média" (Workman, 1999) e a subjetividade com que assumidamente reconta a história não comprometem o tropo do realismo mencionado supra. O esqueleto da intriga não disfarça a Idade Média real nem o "impulso académico" medievalista.

Cabe, porém, notar que, na articulação destes componentes, o universo medieval tem uma presença ténue, restringida às personagens selecionadas para emoldurar as ações da rainha, ou seja, às suas vítimas. Partindo da memória literária, Agustina reinventa a sua personagem desvendando as suas sombras. No entanto, o isolamento do seu tempo, a que se assiste, parece indicar um protocolo de leitura em que a preocupação com o contexto medieval é ultrapassada pela atenção à protagonista per se, enquadrada na perfídia e na sobranceria do humano. Distintamente de outros romances históricos em que Agustina procura inserir a trama no contexto epocal, sem deixar de sobre ele refletir, em "Leonor Telles" as relações entre a protagonista e as personagens com que contracena parecem jogar-se num mundo sem tempo que as torna mais universais do que medievais.

Sublinham este esvaziamento temporal os aforismos típicos da autora bem como a acronia das escassas analogias chamadas a explicar algumas atitudes. Deste modo, não se afigura ser (um)a Idade Média que aqui se representa, mas as razões comuns e atemporais de um percurso tão excessivo e vilipendiado como o de Leonor Teles. E com esta opção, Agustina não intenta absolver a protagonista, mas antes mostrá-la em todo o esplendor de uma maldade condenável, ainda que fascinante, e de uma majestade de dignidade assombrosa. 
À sombra de Lady Macbeth, Leonor Teles ergue-se num sublime diferente e superlativamente negativo.

\section{Bibliografia}

Bessa-Luís, A. (1976). Crónica do Cruzado Osb. Guimarães \& C C Editores.

Bessa-Luís, A. (1973). Santo António. Guimarães \& Cª.

Bessa-Luís, A. (1983). Adivinhas de Pedro e Inês. Guimarães \& C ${ }^{\text {a }}$

Bessa-Luís, A. (2006). Fama e segredo na bistória de Portugal. Editora Guerra \& Paz. [Il. L. M. Castro]

Bessa-Luís, A. (2010). Fama e segredo na bistória de Portugal. Editora Guerra \& Paz. [2. ${ }^{a}$ ed., Il. L. Pepper, Capa: I. Vasco]

Bloom, H. (1997). O Cânone Ocidental. Temas e Debates.

Cláudio, M. (2004). Triunfo de amor. Dom Quixote.

Emery, E. (2009). Medievalism and the Middle Ages. Em K. Fugelso (Ed.), Studies in Medievalism (XVII) Defining Medievalism(s) (pp. 77-85). D. S. Brewer.

Ferré, V. (2010). Introduction. Médiévalisme et théorie: pourquoi maintenant? Itinéraires. http://itineraires.revues.org/1782

Gally, M. e Ferré, V. (2014). Médiévistes et modernistes face au médiéval. Perspectives médiévales, 35. http://journals.openedition.org/peme/5761

Gally, M. (Ed.) (2000). La trace médiévale et les écrivains d'aujourd'bui. PUF.

Gentry, F. G. e Müller, U. (1991). The Reception of the Middle Ages in Germany: An Overview. Em L. J. Workman, J. Chance, F. G. Gentry e J. J. Chance (Ed.), Studies in Medievalism (III:iv) German Medievalism (pp. 399-422). D.S. Brewer.

Gómez Redondo, F. (2006). La narrativa de temática medieval: tipologia de modelos textuales. Em J. Morales (Ed.), Reflexiones sobre la novela bistórica (pp. 319-359). Fundación Fernando Quiñones-Universidad de Cádiz.

Jauss, H. R. (1977). Littérature médiévale et expérience esthétique. Poétique, 31, 322326. 
Lopes, F. (1979). Crónica de D. Pedro. Civilização.

Lopes, F. (1975). Crónica de D. Fernando. Imprensa Nacional-Casa da Moeda.

Lopes, Fernão (1977). Cronica del Rei Dom Foham I. Parte Primeira. Imprensa Nacional-Casa da Moeda.

Machado, A. M. (2017). O medievalismo nas Adivinhas de Pedro e Inês, de Agustina Bessa-Luís. Em T. Azevedo e M. F. Louro (Ed.), Ler a Idade Média hoje. Fontes, texto e tradução (pp. 21-36). Centro de Estudos Humanísticos da Universidade do Minho (CEHUM)-Edições Húmus, Lda.

Mathews, D. (2015). Medievalism: A Critical History. Boydell \& Brewer Ltd.

Nichols, S. G. (2005). Writing the New Middle Ages. PMLA, 120 (2), 422-441. https://www.jstor.org/stable/25486169

Rebelo, L. de S. (1983). A concep̧̧ão do poder em Fernão Lopes. Livros Horizonte.

Ribeiro, A. (1952). Príncipes de Portugal: suas grandezas e misérias. Livros do Brasil.

Shakespeare, W. (1987). A tragédia de Lady Macbeth. Livros do Brasil. [Tradução de João Palma-Ferreira]

Toswell, M. J. (2009). The Tropes of Medievalism. Em K. Fugelso, (Ed.), Studies in Medievalism (XVII) Defining Medievalism(s) (pp. 68-76). Boydell \& Brewer, D. S. Brewer.

Workman, L. (1999). The Future of Medievalism. Medievalism: The Year's Work for 1995, 10, 7-18. [Ed. J. Gallant]

Zumthor, P. (1972). Essai de poétique médiévale. Seuils. 